\title{
Sistemas de Información Geográfica en la protección del recurso hídrico en la microcuenca del río Tabacay, Ecuador
}

\section{Geographic Information Systems in the protection of water resources in the micro-basin of Tabacay River, Ecuador}

\author{
Augusto Martínez ${ }^{1}$, Carlos Matovelle ${ }^{1}$, Luis Astudillo ${ }^{1}$ \\ ${ }^{1}$ Universidad Católica de Cuenca \\ *amartinezv@ucacue.edu.ec
}

DOI: https://doi.org/10.26871/killkana_tecnica.v3i2.256

\begin{abstract}
Resumen
Se presentan los resultados de la utilización del conjunto de Sistemas Información Geográfica (SIG) sumados a criterios de protección de recursos hídricos. El objetivo fundamental es realizar un análisis en la microcuenca del río Tabacay e identificar de qué manera las actividades antrópicas han afectado la calidad y cantidad del agua. La zona de análisis tiene sensibilidad e importancia elevada pues representa el lugar donde se genera el agua para la población de la ciudad de Azogues. Además se ha visto altamente alterada por actividades agropecuarias. Se parte de la recolección de datos mediante un inventario ambiental, en donde se identifican las acciones que se realizan en el suelo de la microcuenca y que podrían producir efectos de contaminación. Se analizan zonas de actividades y su afección al recurso hídrico con el uso de las bondades que tienen los Sitemas de Información Geografica para poder identificar zonas en las cuales sean necesarias las acciones de protección. Además, se han utilizado resultados de imágenes satelitales para obtener el cambio que ha sufrido la vegetación de la microcuenca en el criterio de índice de vegetación de diferencia normalizada, y así definir el área que ha sufrido afecciones en un período de análisis.
\end{abstract}

Palabras clave: Sistemas de Información Geográfica, protección, recursos hídricos, Tabacay.

\begin{abstract}
This study presents the results of using a set of Geographical Information Systems (GIS) along with the water resource protection criteria. The main objective is to carry out an analysis of the Tabacay river micro-basin and identify the way in which anthropogenic activities have affected water quality and quantity. The studied area is of great importance and sensitivity, as it represents the water provision source for the population of the city of Azogues. In addition to this, this area has been highly modified by farming activities. The starting point of this study was data collection which was done through an environmental inventory. Here, the polluting activities carried out on the micro-basin soil were identified. The areas of activity and their effect on water resources were analyzed by using Geographic Information Systems, aimed to identify those sectors in need of protection actions. Additionally, the results of satellite imagery are used to record the changes that have happened to the micro-basin vegetation, according to the normalized difference vegetation index criterion, and thus define the affected area during an analyzed period.
\end{abstract}

Keywords: Geographic Information Systems, protection, water resources, Tabacay.

\section{INTRODUCCIÓN}

Toda actividad que se realice genera un impacto al medio en el que se desarrolla. Estos impactos son más notorios en lugares que no cuentan con un control adecuado de las mismas, así se tiene que la producción agrícola, ganadera e industrial en zonas altas afecta de manera directa (puntual) e indirecta (difusa) al recurso hídrico. Es conocido que en un futuro próximo, el agua tendrá un tratamiento contable [1], por tal motivo toda acción que se pueda desarrollar a favor de preservar el recurso es significante.
El concepto de Impacto Ambiental ha producido un giro significativo en el modo de encarar los procesos de planificación, el diseño y ejecución de las actividades humanas, la evaluación de la viabilidad de la actuación se basaba en criterios técnicos, económicos y sociales, que en la actualidad incluyen los criterios ambientales [2]. Estos impactos se pueden analizar de una manera más precisa con el procesamiento de datos y la ayuda de los Sistemas de Información Geográfica (SIG), que brindan una referencia clara de la magnitud y ubicación de la contaminación, lo 
cual permite enfocar esfuerzos y tomar decisiones que sean viables y produzcan resultados satisfactorios.

Previo al procesamiento y análisis de todos los datos, es necesario incluir información propia, por lo que se recurre a los inventarios ambientales. Estos permiten conocer el estado del lugar y sus condiciones ambientales [3] [4] . De esta forma se puede tener un idea clara de lo que ocurre en la zona de estudio, además de vincular la información digital disponible con la realidad tangible de la zona.

Con la utilización de las herramientas de los Sistemas de Información Geográfica se establecen y generan mapas temáticos de la microcuenca que cuentan con actividades antrópicas, recurso hídrico, tipo de suelo, pendientes, zonas pobladas y boscosas. Así se realiza un análisis integral de la zona de estudio.

\section{CONCEPTOS TEÓRICOS}

\section{A. Inventario ambiental}

Un inventario es una actividad que se realiza previa al procesamiento de datos para conocer con precisión sobre el lugar en el que se va a trabajar y todas las acciones que se realicen en él. Vincular un inventario ambiental previo al procesamiento de datos con SIG, da un vínculo a la investigación en donde se analiza información digital con información tangible recopilada en campo.

El propósito práctico de un levantamiento de suelos es hacer posible predicciones más numerosas, más exactas y más útiles para propósitos específicos que han podido haberse hecho. [5]

\section{B. Actividades antrópicas en zonas andinas ecuatorianas}

La región andina, o más conocida como Sierra, es una de las cuatro regiones naturales de Ecuador. Esta zona atraviesa de norte a sur al país y está conformada por las provincias de Pichincha, Carchi, Tungurahua, Chimborazo, Cañar, Azuay, Loja, Imbabura, Bolívar y Cotopaxi. [6] A pesar de la topografía abrupta de los ecosistemas de alta montaña, las condiciones climáticas de las cordilleras han resultado bastante favorables para el establecimiento de la mayor cantidad de la población humana, lo que ha provocado la disminución progresiva de escenarios naturales, debido a la adecuación de tierras para sistemas agropecuarios y por la expansión de las ciudades [7] .

La provincia de Cañar, perteneciente a la zona administrativa 6 , sigue el mismo patrón de producción de la región. Es una zona que presenta bajo contenido de materia orgánica y una baja susceptibilidad a la erosión. La principal actividad productiva corresponde al sector terciario, que es la prestación de servicios que corresponden a un $70 \%$, el sector manufacturero un $13 \%$ y la agricultura, ganadería, caza y silvicultura representan un $16 \%$. La industria no toma fuerza todavía por lo que se tiene solo a la empresa cementera Guapán como pionera en este sector. [8]

\section{Tipos de contaminación}

\section{Contaminación puntual}

Son fuentes de contaminación puntual todas las descargas de contaminantes que afectan a zonas localizadas, por lo general los sitios que más sufren las consecuencias son los cuerpos de agua superficial. Este tipo de afección es fácil de localizar, monitorear y tratar. Este tipo de contaminación es más intensa en el lugar de origen y conforme avanza en el cuerpo receptor disminuye su concentración.[9]

\section{Contaminación difusa}

Las fuentes de contaminación difusa son aquellas que descargan contaminantes al agua superficial y subterránea en grandes áreas de terreno, por lo que no es fácil localizar un foco de contaminación. Esta situación genera graves problemas, con el paso del tiempo la contaminación alcanza zonas muy extensas que afectan al suelo y agua del lugar.

Este tipo de contaminación se agrava en dependencia del lugar en el que se de, zonas con mayor pendiente y con suelos poco permeables son los más afectados. [10]

La contaminación al recurso hídrico tiene dos orígenes: naturales (desastres naturales, precipitaciones, procesos biológicos); y antrópicos (urbana, industrial, agrícola) que según la naturaleza de los contaminantes estos pueden ser físicos, químicos, inorgánicos y biológicos.

Según su localización se puede establecer si son puntuales: cuando los contaminantes son desechados de manera directa al recurso hídrico; y, difusa: cuando los contaminantes llegan de manera indirecta o dependen de otro medio. Un claro ejemplo de esto puede ser la contaminación por plaguicidas, los cuales son transportados mediante escorrentías ya sean superficiales o subterráneas.

\section{Sistemas de Información Geográfica (SIG)}

Los SIG son una integración de hardware, software y datos geográficos diseñados de tal manera que permiten manipular, almacenar, y analizar la información geográficamente referenciada. Tienen la finalidad de resolver todo tipo de problema de gestión y planificación dentro de cualquier área de estudio que sea posible su aplicación. En la actualidad forman parte de un poderoso conjunto de herramientas dentro del área de las ingenierías. [11]

Los SIG trabajan con datos vectoriales y datos ráster. Los datos vectoriales son el conjunto de elementos geométricos y georefenciados que forman entidades; y los datos ráster es información que está formada por pixeles con un valor predeterminado, de esa manera se pueden realizar varios análisis vinculando las características de estos datos. Además de información disponible como ortofotos, que son imágenes aéreas e imágenes satelitales para crear mapas temáticos con información. 


\section{DESARROLLO}

Las operaciones de Análisis Espacial son cada vez más efectivas a la hora de tomar decisiones en cualquiera de las ramas del desarrollo [12]; dentro del manejo, gestión y protección del recurso hídrico cada vez son más empleados. En varios países dentro de Europa y América se han creado Confederaciones Hidrográficas, cuyo objetivo es gestionar y planificar los recursos hídricos de una o más cuencas hidrográficas, además de proteger el dominio público hidráulico, controlar la calidad de las aguas y crear y mantener las infraestructuras necesarias para el riego y el abastecimiento de agua, disponen de IDE y geoportales en los que ponen a disposición múltiple información espacial [13]. Dentro de esta investigación se propone el trabajo con la información espacial disponible y procesada, teniendo así una primera fuente de información que permita gestionar el Recurso Agua en la microcuenca.

\section{A. Inventario de actividades}

Para realizar el inventario de las actividades antrópicas que se desarrollan en la microcuenca del río Tabacay, se elabora una ficha de campo que sigue la metodología establecida por la FAO en su Manual para la recolección integrada de datos de campo adaptándola a las necesidades del estudio, con la cual se obtienen de manera general los diferentes usos de suelo, su ubicación geográfica, flora y fauna predominante del lugar, tipo de contaminación que generan al recurso hídrico y observaciones puntuales de cada caso.

El avance de las fronteras productivas se ve reflejada en toda la microcuenca, y tiene como consecuencia la destrucción de la mayor parte de los bosques nativos y páramos, que han sido reemplazados por potreros con cultivos de forraje para ganado y pequeñas zonas para producción agrícola de ciclos cortos y anuales como es el maíz y las hortalizas. Las actividades agrícolas y ganaderas se desarrollan en toda la región a pesar de las duras condiciones topográficas que presenta la microcuenca. Estos factores han sido determinantes para que se de paso a una mayor contaminación puntual y difusa al recurso hídrico.

Se realiza un análisis y levantamiento de información de viviendas para determinar la contaminación puntual y difusa que se genera por vertidos de aguas residuales sin depuración, debido a un mala planificación y ordenamiento territorial. Se consideran criterios de distancia para diferenciar el tipo de contaminación. Desde la red hídrica hacia los vertidos con una distancia de 100 metros se considera vertido puntual, pues puede realizar directamente al cuerpo de agua. Las otras viviendas se consideran contaminación por la presencia de pozos sépticos sin las medidas de construcción adecuadas.

\section{B. Análisis de imágenes satelitales (Ortofotos, Landsat)}

Para realizar este proceso se analizan datos del Sistema Nacional de Información y Gestión de Tierras Rurales e Infraestructura Tecnológica (SIGTIERRAS). El mosaico de ortofotos de la microcuenca del río Tabacay con una escala 1:50.000 con pixeles de $3 \mathrm{~m} \times 3 \mathrm{~m}$ el cual sirve para analizar el uso de suelo actual. También se descargan las imágenes generadas por el satélite Landsat 8; cuyas características permiten calcular el Índice de Vegetación de Diferencia Normalizada (NDVI) que genera información en formato raster donde cada pixel tiene un valor que va desde $-1 \mathrm{a}+1$.

Los cálculos por píxel arrojan datos numéricos que van desde -1 a +1 , sin embargo, no existen hojas que den valores cercanos a $0(0.2$ a 0.45$)$, este dato corresponde a zonas con escasa vegetación, praderas, tundra, desierto o vegetación bajo algún tipo de estrés. Los valores más cercanos a $1(>0.5)$ indican una vegetación densa y en buenas condiciones de desarrollo, mientras que los valores negativos se pueden dar por la presencia de nubes, nieve, agua, suelo sin cobertura vegetal o rocas.

\section{Mapas temáticos}

Los mapas se generan a partir de la información recolectada en el campo, descargada de SIGTIERRAS y la obtenida en la caracterización hidrológica y morfológica de la microcuenca del río Tabacay. Esta información es analizada mediante metodologías de diferentes autores y organismos como es de la Organización de las Naciones Unidas para la Alimentación y la Agricultura (FAO) en su manual de estudio y planificación de cuencas de montaña, donde establece el riesgo de erosión según la pendiente y la profundidad del suelo.

Se generan pendientes y se calcula el riesgo de erosión de la microcuenca según lo establecido en el manual de la FAO, que se presenta en la Tabla I

\begin{tabular}{|c|c|c|c|}
\hline Grados $^{\circ}$ & Porcentaje $\%$ & Tipo & Riesgo \\
\hline$<7$ & $<12$ & Plana a suave & Muy bajo \\
\hline $7-15$ & $12-27$ & Moderada & Bajo \\
\hline $15-20$ & $27-36$ & Fuerte & Medio \\
\hline $20-25$ & $36-47$ & Muy fuerte & Medio alto \\
\hline $25-30$ & $47-58$ & Acusada & Alto \\
\hline$>30$ & 58 & Muy acusada & Muy alto \\
\hline
\end{tabular}

TABLA I: Riesgos de erosión según la pendiente.

Luego se procede a realizar la clasificación de riesgo de pérdida de suelo según la profundidad, como se muestra en la Tabla II. En la cual se hace referencia a la profundidad efectiva en donde las raíces de las plantas existentes pueden penetrar sin dificultad. Para realizar esta clasificación se utiliza la información obtenida de SIGTIERRAS sobre el uso de suelo de la microcuenca.

Una vez generados los datos se realiza la clasificación del riesgo potencial de degradación del suelo (Figura 1), con el objetivo de conocer las zonas dentro de la microcuenca que representan mayores amenazas en cuanto a su conservación y actividades que en estas se generan.

El riesgo es representado mediante un color en específico con su respectivo código Figura 2 


\begin{tabular}{|c|c|c|}
\hline Profundidad & Tipo & Riesgo \\
\hline$<20 \mathrm{~cm}$ & Muy someros & Muy alto \\
\hline $20-50 \mathrm{~cm}$ & Someros & Medio alto \\
\hline $50-90 \mathrm{~cm}$ & Moderadamente profundos & Medio \\
\hline$>90 \mathrm{~cm}$ & Profundos & Bajo \\
\hline
\end{tabular}

TABLA II: Riesgo de pérdida de suelo según la profundidad

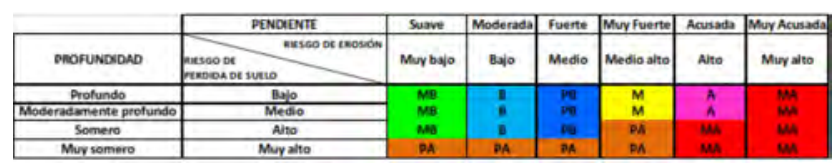

Fig. 1: Riesgo potencial de degradación de suelo.

\section{RESUlTADOS Y ANÁlisis}

En la Figura 3 se pueden observar las diferentes actividades antrópicas que se desarrollan en la microcuenca al igual que su respectivo uso de suelo. Este mapa ha sido generado con información obtenida del Sistema Nacional de Información de Tierras Rurales e Infraestructura Tecnológica (SIGTIERRAS). Mediante visitas in situ y análisis de ortofotos se pudo determinar qué tipo de actividad se desarrolla. La información está conformada por un sistema vectorial donde cada capa representa una actividad en particular y los detalles generales de la misma.

En la Figura 4 se pueden observar las pendientes y el riesgo de erosión que tiene la microcuenca, mismas que han sido elaboradas con la metodología establecida por la FAO donde se estima la posibilidad de erosión del suelo mediante una clasificación de las pendientes en seis rangos. Se analiza el riesgo desde muy bajo representado por color verde, que tiene una pendiente menor a $7^{\circ}$ que sería la zona más ideal para realizar cualquier actividad puesto que no representa dificultades mayores en cuanto a su morfología. El riesgo de erosión muy alto es representado por el color rojo, el cual tiene una pendiente mayor a $30^{\circ}$, lo que indica que es un lugar que no es propicio para desarrollar actividades antrópicas puesto que el suelo perdería rápidamente sus características y se daría paso a una degradación constante. En investigaciones propias sobre la incidencia de la pendiente [14], se explica muy claro que mayor inclinación del suelo existe más efecto de la erosión y mayor pérdida de productividad.

En la Figura 5 se puede observar el tipo de suelo, profundidad aproximada y el riesgo de pérdida del mismo por efectos de la erosión. La clasificación de la profundidad se obtuvo analizando los distintos usos de suelo y el alcance máximo de profundidad que las raíces de la vegetación existente puedan alcanzar. El riesgo de erosión está clasificado desde muy bajo, representado por suelos profundos que son los que no han tenido intervención alguna y mantienen sus propiedades donde sus raíces alcanzan profundidades mayores a los $90 \mathrm{~cm}$, y hasta una erosión muy alta que es producida por suelos muy someros donde

\begin{tabular}{|c|c|c|}
\hline RIESGO & CÓDIGO & COLOR \\
\hline MUY BAJO & MB & \\
\hline BAJO & B & \\
\hline POCO BAJO & PB & \\
\hline MEDIO & M & \\
\hline POCO ALTO & PA & \\
\hline ALTO & A & \\
\hline MUY ALTO & MA & \\
\hline
\end{tabular}

Fig. 2: Color y código del riesgo potencial de pérdida de suelo.

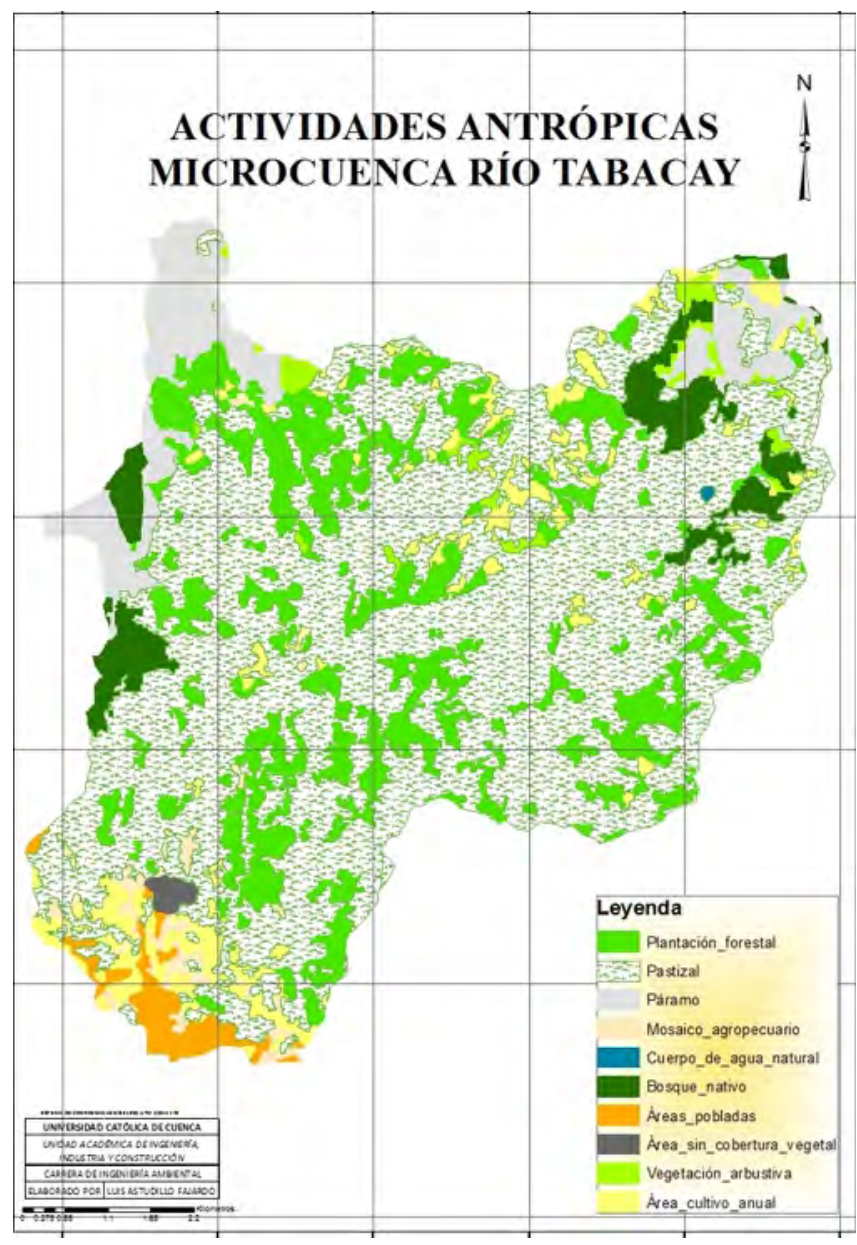

Fig. 3: Mapa de actividades antrópicas en la microcuenca.

sus raíces alcanzan hasta una profundidad de $20 \mathrm{~cm}$ como máximo. Estos son los suelos que han sido fuertemente intervenidos como potreros y zonas agrícolas.

En el mapa se puede observar que gran parte del territorio de la microcuenca tiene profundidades que hacen relación a suelos muy someros, lo cual es un resultado del cambio de uso por las actividades agropecuarias que se realizan en la zona. Esto representa un riesgo muy alto de erosión por profundidad del suelo y representa problemas 


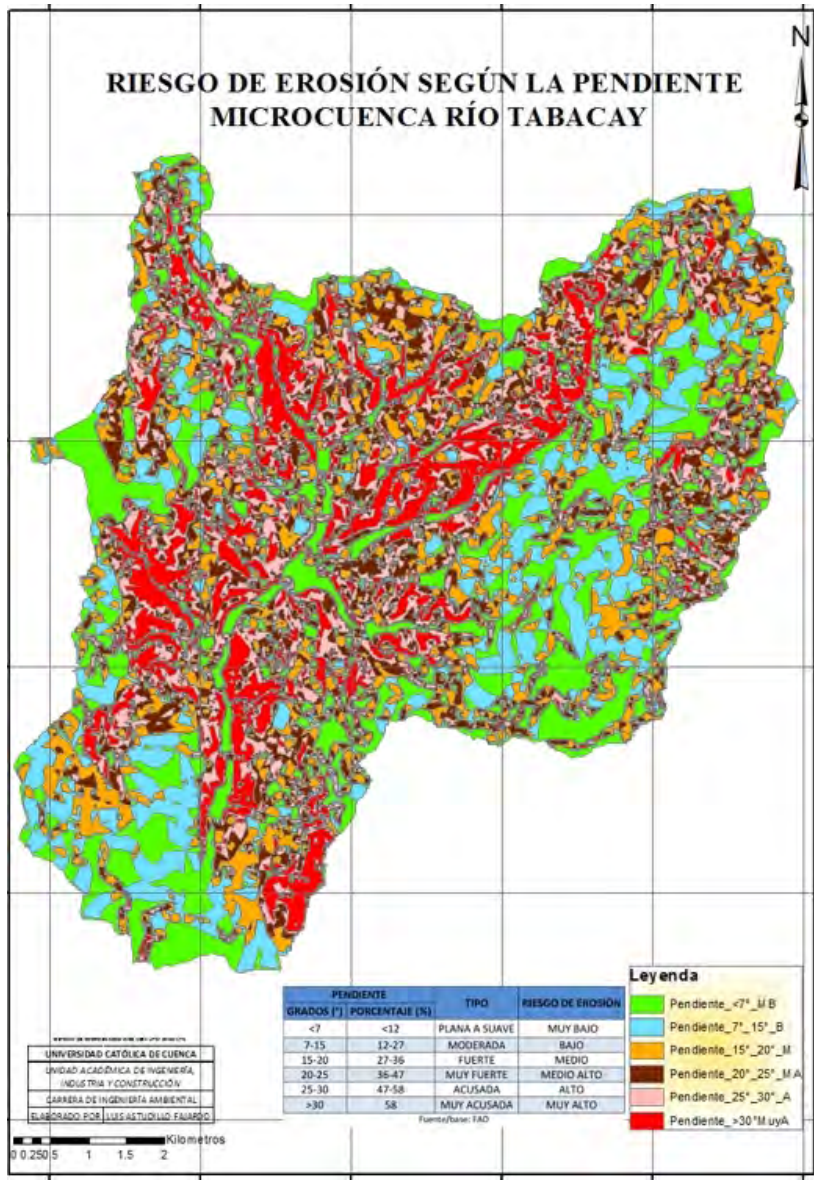

Fig. 4: Mapa de riesgo de erosión según la pendiente.

de calidad del recurso hídrico por el arrastre de sólidos suspendidos con la escorrentía, luego de eventos de precipitación.

Al momento de combinar estos dos criterios, se determina el riesgo total de pérdida de suelo que existe en la microcuenca, de acuerdo a la metodología planteada por la FAO para el estudio y planificación de cuencas de montaña. En la Figura 6 se puede observar el riesgo potencial de degradación del territorio de la microcuenca, que se genera al cruzar la información de las pendientes con la profundidad del suelo. Se obtiene un rango de erosión que va desde muy bajo representado por el color verde, que indica los lugares más estables e ideales para realizar alguna actividad, a muy alto simbolizado por el color rojo que figura las zonas más propensas a sufrir degradación si se realiza alguna actividad antrópica.

En las zonas en donde coinciden pendientes elevadas con usos de suelo someros, es en donde existe mayor pérdida de suelo, y por ende mayor arrastre de sólidos con la escorrentía, esto permite realizar un análisis de zona de mayor alteración al recurso hídrico.

Se revisa la contaminación puntual y difusa que existe en la microcuenca. Como se ha explicado, en la

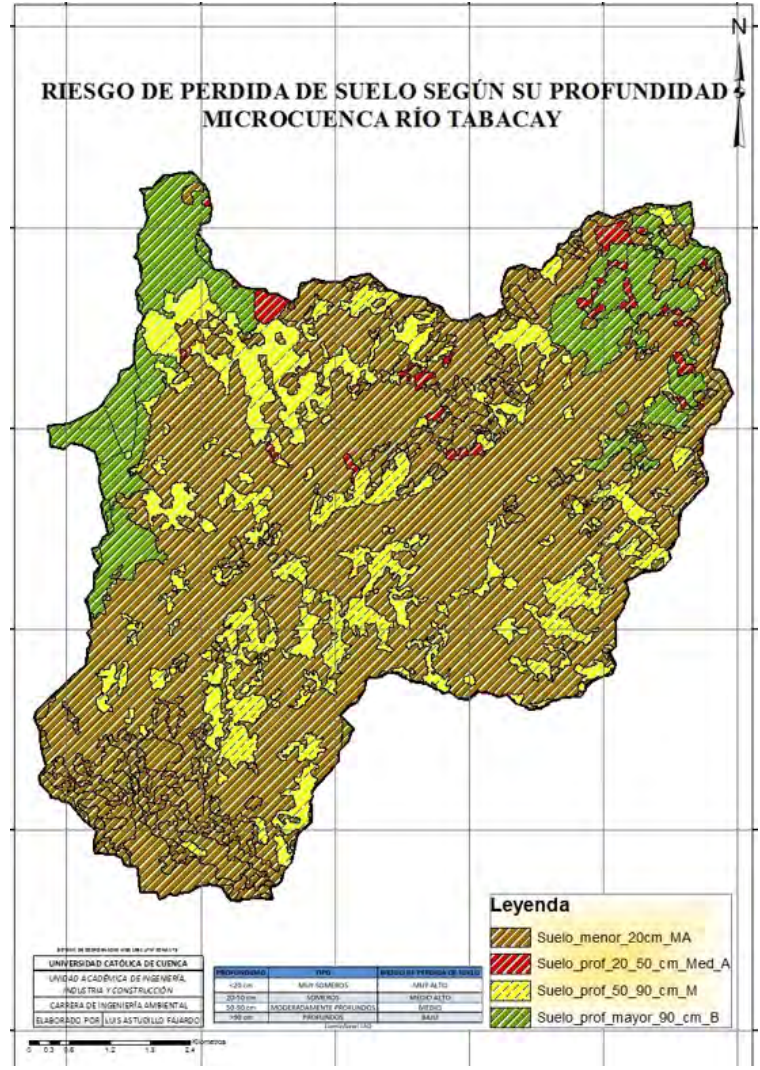

Fig. 5: Mapa de riesgo de erosión por profundidad de suelo.

metodología se consideran criterios de distancia a los ríos para diferenciar el tipo de contaminación, además se consideran las zonas de mayor actividad agropecuaria como contaminación difusa por el arrastre de los contaminantes, principalmente materia orgánica y nutrientes. Algunas opciones de estimación de contaminación difusa se desarrollan, así como la selección de las mejores prácticas de conservación, que pueden ser adaptadas por la población local y bajo la supervisión a largo plazo para evaluar la reducción de los aportes de contaminantes [15].

En el mapa que se presenta en la Figura 7 se puede observar al área de la microcuenca que es afectada por la contaminación puntual ocasionada por las zonas residenciales. Esto se obtiene mediante la generación de una zona de influencia donde se considera una distancia de $100 \mathrm{~m}$ desde la red hídrica hacia las casas que pueden generar contaminación puntual, puesto que al no contar con un sistema de alcantarillado en la zona rural de la microcuenca los habitantes acostumbran a utilizar pozos sépticos para sus aguas negras, las cuales llegan a los cauces principales o en algunos de los casos estas son conducidas directamente mediante tuberías a las quebradas o al río.

En la Figura 8 se presenta al área de la microcuenca que sufre contaminación difusa por parte de las zonas residenciales. Esta se obtiene mediante la generación de una zona de influencia considerando una distancia de $500 \mathrm{~m}$ desde las 


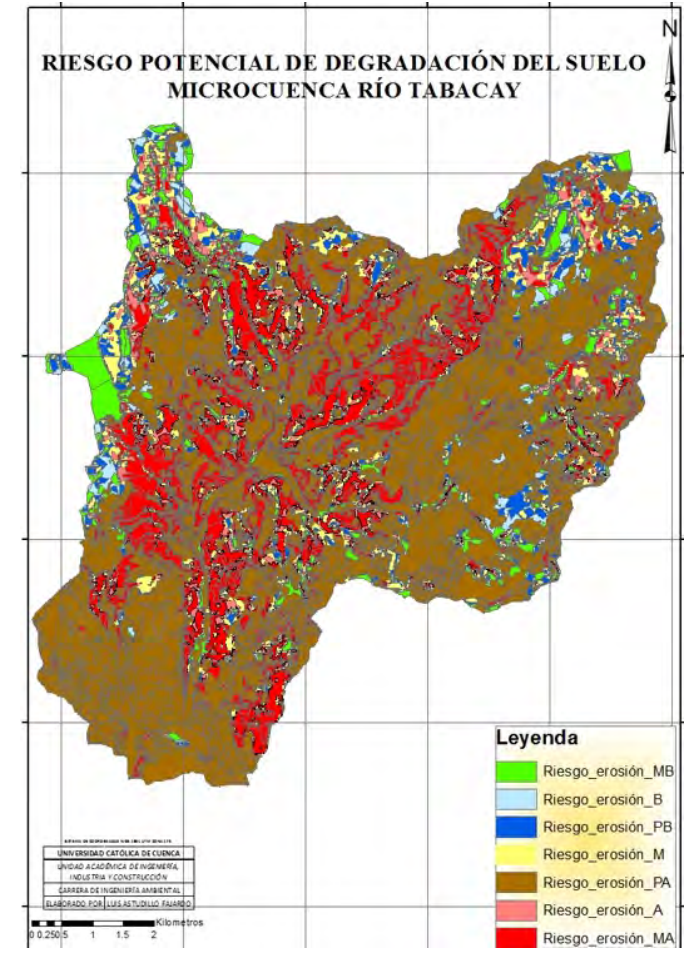

Fig. 6: Mapa de riesgo potencial de degradación de suelo.

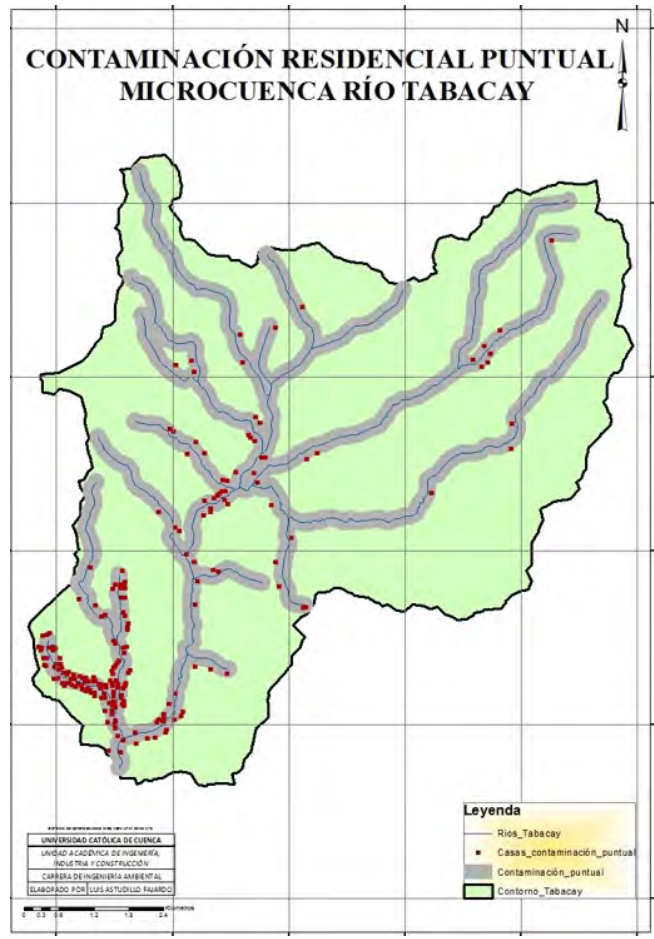

Fig. 7: Mapa de contaminación puntual casas que existen hacia la red hídrica sin considerar las que generan contaminación puntual. Todas aquellas que estén dentro del rango de $500 \mathrm{~m}$ y que lleguen hasta las quebradas o el río generan contaminación difusa y las que no, solo ocasionan contaminación al suelo.

Los posibles focos de contaminación difusa (Figura 9) se puede generar por el uso del suelo en pastizales, mosaicos agropecuarios y cultivos anuales a más de las condiciones morfológicas de la microcuenca, puesto que estas actividades generan una pérdida de las características físicas y dan paso a una mayor degradación, misma que se puede observar en épocas de precipitación donde la red hídrica en cuestión de minutos cambia su color por el gran arrastre de sólidos de las zonas intervenidas. Se ha considerado todo el levantamiento de información, la generación de información mediante SIG y los puntos encontrados de mayor importancia son los lugares en donde podrían considerarse óptimos para un sistema de monitoreo.

Se analizan también las ortofotos de la microcuenca, y se tiene en cuenta la alteración que han sufrido los márgenes del río. En la Figura 10 se ve la red hídrica y bosque de ribera de la microcuenca. El área de influencia de la zona de bosque de ribera se genera teniendo en cuenta el Acuerdo Ministerial 128 del Ministerio del Ambiente donde manifiesta que si el río o quebrada tiene hasta 3 $\mathrm{m}$ de ancho se debe mantener un área de protección de mínimo $10 \mathrm{~m}$ en las márgenes para evitar contaminación, deslizamientos e inundaciones. aA más de eso estos sirven como agentes biológicos, evitan la contaminación directa, estabilizan las orillas, disminuyen la escorrentía, mantienen la humedad del suelo, mejoran el paisaje y dan sombra para los animales.

Parte interesante del estudio es el análisis de imágenes satelitales con la ayuda de los SIG. Se han analizado dos imágenes satelitales en fechas iguales de años diferentes para obtener el Índice de Vegetación Diferencial Normalizada y verificar los cambios que ha sufrido la vegetación en el transcurso de esos años.

En la Figura 11 se puede observar el Índice de Vegetación de Diferencia Normalizada (NDVI) del año 2013 de la microcuenca del río Tabacay mismo que se utiliza para estimar la cantidad, calidad y desarrollo de la vegetación con base a la medición de la intensidad de la radiación de ciertas bandas del espectro electromagnético que la vegetación emite o refleja, donde cada píxel de la imagen tiene un valor que va desde -1 a 1 , los valores de -1 a 0 representan zonas pobladas, infraestructuras, ríos, lagunas o nubes, mientras que los que tienen valores mayores a 0 y hasta 0.5 representan zonas que tienen poca vegetación como potreros o cultivos, y los que tienen valores de 0.5 a 1 son los lugares donde todavía existe buena vegetación siendo la que tienen valor de 1 la zona con vegetación, más exuberante y sana. En la Figura 12 se observa el índice para el mismo día, pero en el año 2016 y es evidente el cambio que ha existido con el simple análisis de los colores de las imágenes.

Para realizar un cálculo preciso del cambio que ha sufrido la vegetación, se procesan los ráster de los NDVI en los 


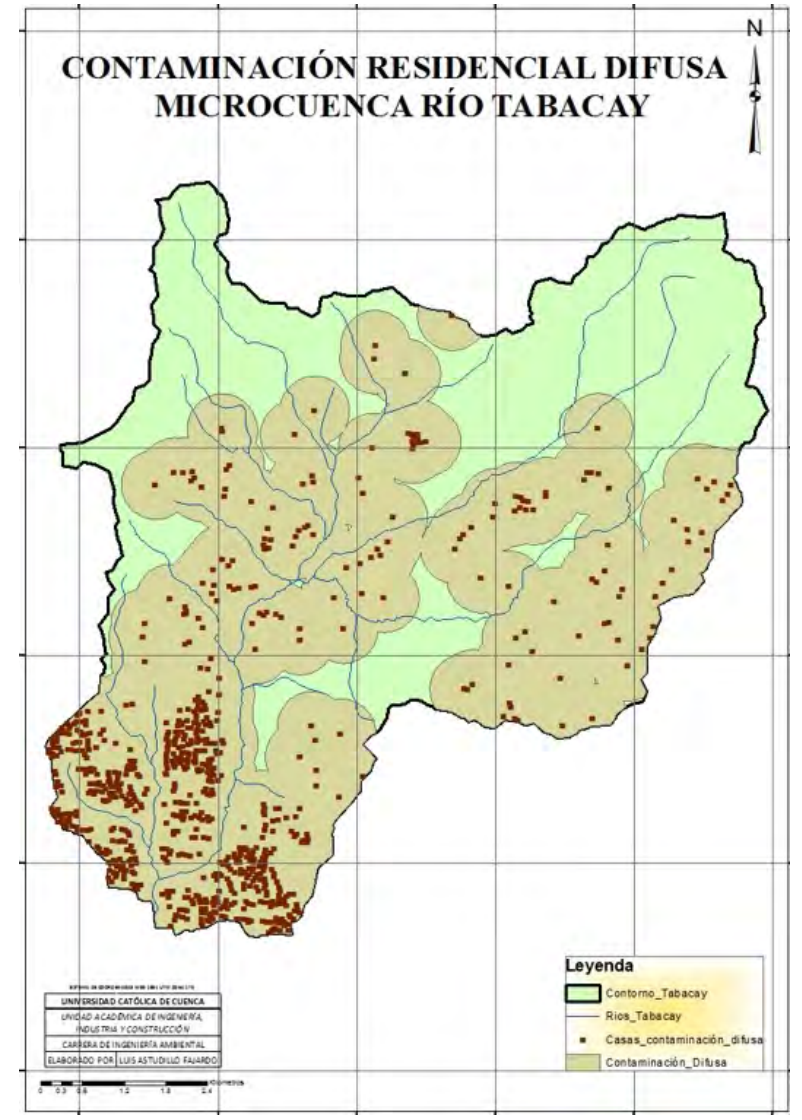

Fig. 8: Mapa de contaminación difusa

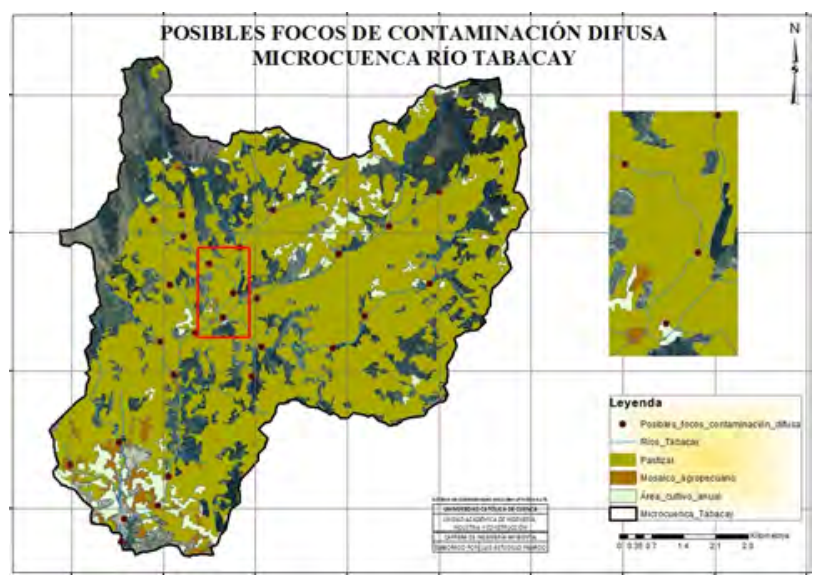

Fig. 9: Focos de contaminación difusa por actividades agropecuarias

diferentes años. En la Figura 13 se muestran los resultados del cambio de uso de suelo que ha tenido la microcuenca en el transcurso de cuatro años que es de $5.34 \mathrm{~km}^{2}$ que equivale a $7.98 \%$ del área total, mismo que se obtiene mediante el cruce de la información del NDVI de los años 2013 y 2016 de la microcuenca del río Tabacay donde se realiza una resta de los valores de sus píxeles, desde el último año teniendo en cuenta que a valores iguales la resta

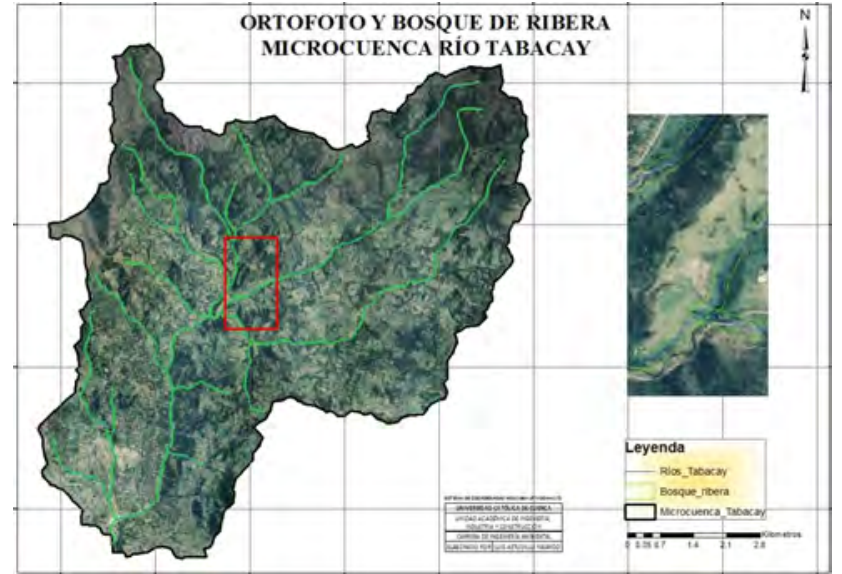

Fig. 10: Ortofoto y bosque de ribera

será 0 , lo que significa que el uso de suelo sigue siendo el mismo mientras que los valores de 1 indican que en ese lapso de tiempo existió un cambio significativo en cuanto a la cobertura de suelo del lugar. Propuestas similares se observan en estudios como [16], en donde el procesamiento y análisis de la información geoespacial para el cálculo de NDVI en el análisis de suelos en centros urbanos forestados ha permitido evaluar el rendimiento de estos procesos.

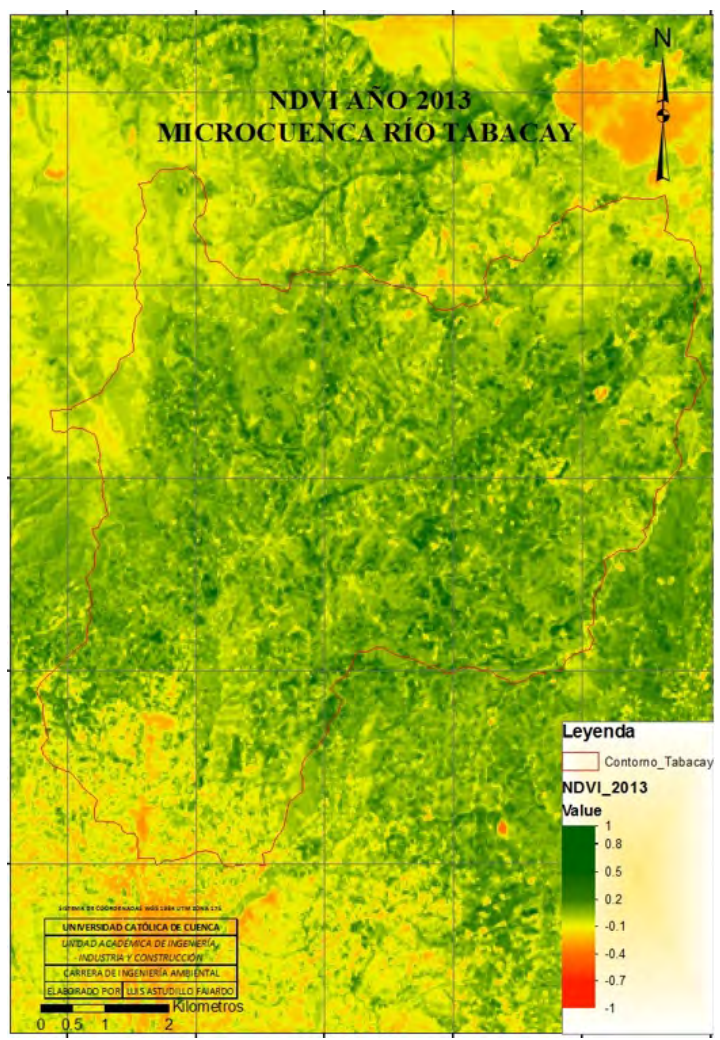

Fig. 11: NDVI año 2013 


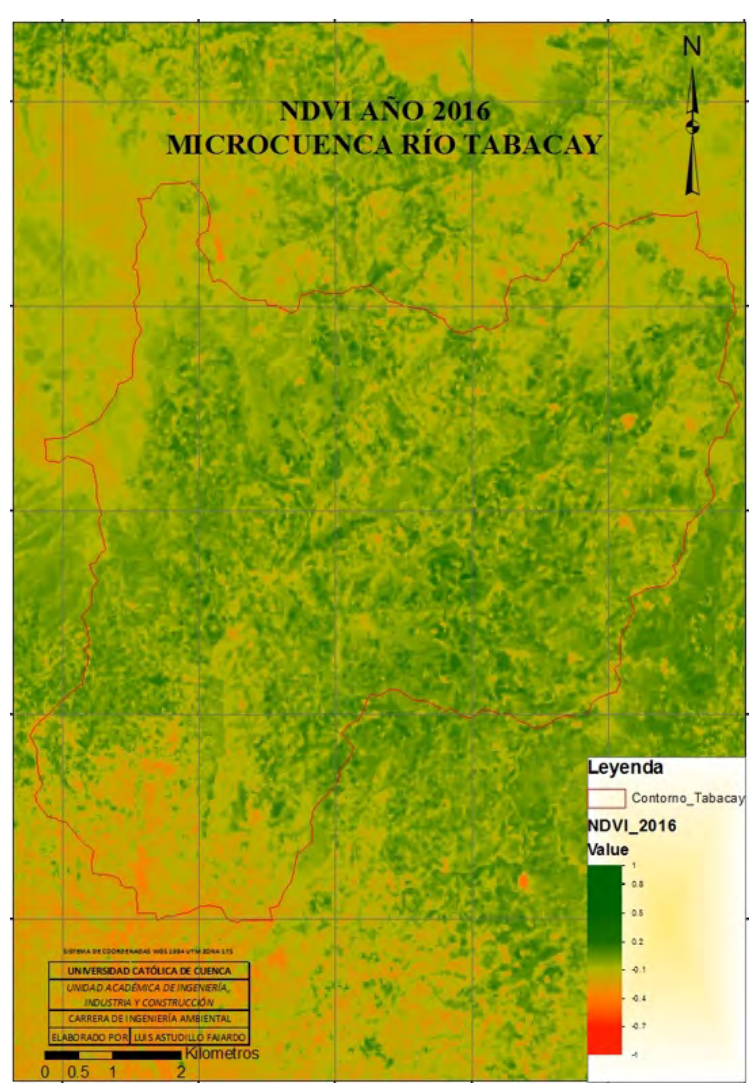

Fig. 12: NDVI año 2016

\section{CONCLUSIONES}

En cuencas hidrográficas que tengan prioridad dentro de los Planes de Manejo por tener características particulares, el uso de los Sistemas de Información Geográfica aporta con otro tipo de visualización frente a los problemas que presentan las metodologías convencionales. La microcuenca del río Tabacay tiene una importancia particular por ser la única fuente de abastecimiento de agua para la ciudad y en donde los usos que se le ha dado para actividades de ganadería y agricultura han degradado la calidad y cantidad del agua, por ese motivo al momento de utilizar los SIG se obtuvieron aportaciones significativas y de gran interés para los gestores de territorio.

Los usos de suelo que tiene la microcuenca son diversos, predominando los ganaderos y agropecuarios. Esto compromete la estabilidad del suelo y la regulación del agua. El desarrollo de estas actividades provoca problemas de contaminación difusa en sectores marcados, los cuales se pueden identificar luego del procesamiento de datos con SIG.

El crecimiento poblacional no programado provocó que existan viviendas sin servicios de saneamiento, lo que contribuye con la contaminación del recurso hídrico. Se observa en los análisis que gran parte del territorio de la microcuenca se muestra afectada por este problema de contaminación.

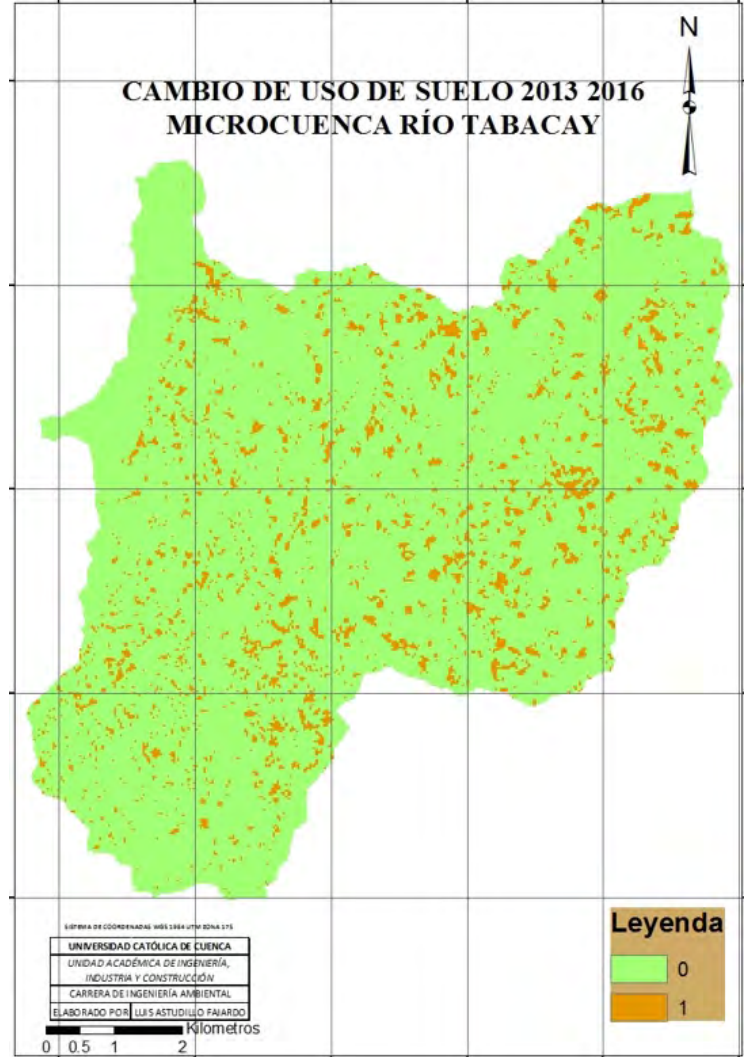

Fig. 13: Cambio de uso de suelo

Los cambios que ha sufrido la vegetación son altos en el período del tiempo de análisis, pues alrededor del $8 \%$ de la microcuenca ha cambiado la calidad de su vegetación. Esto no solo indica que la vegetación se ha perdido, si no que también su índice de calidad ha disminuido por factores secundarios, como podrían ser la disminución de la calidad del suelo por el cambio de actividades y usos. Toda esta perspectiva amplía del estado de la microcuenca y su afección en el recurso hídrico ha sido analizado mediante el procesamiento de la información espacial disponible.

\section{REFERENCIAS}

[1] F.A. Ledezma - Perizza, Empleo de Sistemas de Información Geográfica, Datos de Sensoramiento Remoto y Fuentes de Acceso Libre Global, como herramienta para modelar agua, energía y cambio climático en Bolivia, Acta Nova, 2012, v.5 n.4, pp 477 - 520.

[2] R. Montoya - Ayala, J.C. García - Palomares, J. Padilla Ramirez, Utilización de un SIG para la determinación del impacto ambiental generado por actividades agrícolas, ganadera e industriales: el caso del valle de Zapotitlán en la reserva de la biosfera de Tehuacán Cuicatlán, Boletín de la A.G.E, n 38, 2004, pp 115-129.

[3] S. Cotán - Pinto Arroyo, Evaluación del Impacto Ambiental (EvIA), Escuela de Organización Industrial, 2007. 
[4] GEOALCALI, Estudio de Impacto Ambiental Refundido Proyecto de Explotación Mina "Muga", Inventario Ambiental: Estudio del Estado del Lugar y Condiciones Ambientales, 2018.

[5] D. Dent, A. Young, Soil Survey and Land Conservation. HarperCollins Publishers Ltd, 1981.

[6] Plan Nacional del Buen Vivir. Ecuador, 2014.

[7] A.M. Torres, E.J. Peña, O. Zúñiga, J.A. Peña, Evaluación del impacto de actividades antrópicas en el almacenamiento de carbono en biomasa vegetal en ecosistemas de alta montaña de Colombia, 2012, pp $132-142$.

[8] B. Bonilla, Agenda Zonal 7 - Zona Sur. Ecuador, 2016.

[9] S. González, Contaminación difusa de las aguas. Inia Tierra Adentro, 2007, pp. 21-25.

[10] E. Luis, Contaminación del agua. Universidad de Navarra, 2007, pp. 26.

[11] J. Luis, A. Gárate, \& M. Monzón, Sistemas de Información Geográfica Gestión Integral del Litoral Gestión Integral del Litoral, 2009.

[12] Y. Sánchez-Cruz, M. Amorós Nuñez, Gestión del agua urbana mediante Análsis Espacial en los SIG. Ingeniería Hidráulica y Ambiental, 2012, pp. 58-71

[13] E. Quirós, M.E. Polo, Recursos abiertos de información geográfica para investigación y documentación científica. Revista española de Documentación Científica, 2018, 41 (3): e214

[14] F. Sancho, M. Villatoro, Efecto de la posición en la pendiente sobre la productividad de tres secuencias de suelos en ambientes rústicos de Costa Rica, Agronomía Costarricense, 2005, 159-174.

[15] M.A. Mijangos Carro, R. González Villela, L.A. Bravo Inclán, M. Alba Uriostegui, B.M. Evans, Estudio de fuentes de contaminación puntual y difusa en las subcuencas del lago de Tuxpan y río Tomatal, Iguala, Gro., México, Memorias de resúmenes en extenso SELPERXXI-México-UACJ, 2015.

[16] M.E. Arboit, D.S. Maglione, Análisis multitemporal y multiespacial del índice de vegetación de diferencia normalizada (NDVI) y del índice de vegetación ajustado al suelo (SAVI) en centros urbanos forestados y oasis irrigados, con climas secos. Boletín de Estudios Geográficos, 2018, pp 13 - 60.

Recibido: 6 de abril de 2018

Aceptado: 10 de junio de 2019

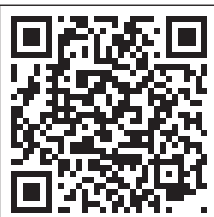


